\title{
On the supposed limits of physicalist theories of mind
}

\author{
Jonathan E. Dorsey
}

Published online: 23 May 2010

(C) The Author(s) 2010. This article is published with open access at Springerlink.com

\begin{abstract}
Is physicalism compatible with either panpsychism or so-called "fundamental mentality"? Minimal physicalism, I contend, is compatible with both. We should therefore jettison the "No Fundamental Mentality" constraint, a proposed constraint on the definition of "the physical", not to mention the false limits it places on physicalist theories of mind.
\end{abstract}

Keywords The physical · Physicalism - Minimal physicalism - Panpsychism . Panpsychistic materialism - The fundamental · Fundamental mentality · Configurationism · Compatible $\cdot$ Compatibility $\cdot$ NFM constraint

\section{When the chips are down...}

Is physicalism compatible with either panpsychism or so-called "fundamental mentality"? If it is compatible with both, our definition of "the physical" is not subject to the "No Fundamental Mentality (or NFM)"1 constraint: roughly, that, on pain of not being physical, fundamental physical entities (e.g., electrons) cannot instantiate mental properties. The physicalist would thus be free to posit fundamental mentality.

\footnotetext{
1 I borrow the phrases "No Fundamental Mentality constraint" and "NFM constraint" from Jessica Wilson (2006).
}

\section{J. E. Dorsey $(\varangle)$}

University of California, Davis, Davis, CA, USA

e-mail: jedorsey@ucdavis.edu

\section{J. E. Dorsey}

1240 Social Sciences and Humanities Building, University of California Davis, One Shields Ave., Davis, CA 95616, USA 
This theoretical freedom may be exactly what the physicalist needs. The NFM constraint clearly takes cards from the physicalist's hand, cards worth playing when the chips are down. Specifically, a theorist facing the unpleasant choice between eliminative materialism and an explanatory gap might reconsider the virtues of fundamental mentality. ${ }^{2}$

Fortunately, physicalism is compatible with both. My position rests on three key ideas:

(i) That, of two senses of 'fundamental mentality', only one is incompatible with physicalism, which, as it turns out, is not the sense relevant to the NFM constraint.

(ii) That physicalism does not entail (and should not be confused with) what I call 'configurationism', the view that only highly-configured entities can have mental properties.

(iii) That physicalism does not even entail (and should not be confused with) what I call 'weak configurationism', the view that only configured entities (whether or not they are highly-configured) can have mental properties.

Together, I contend, these ideas suggest that physicalism is compatible with fundamental mentality, as well as panpsychism. We should therefore jettison the NFM constraint and the false limits it places on physicalist theories of mind.

\section{Minimal physicalism (a caveat)}

Throughout the following discussion the specific view of interest is minimal physicalism, ${ }^{3}$ i.e., the minimal thesis one can endorse while remaining a physicalist. One may contrast minimal physicalism with mainstream physicalism, i.e., the majority view of those who currently consider themselves physicalists.

Though mainstream physicalism is no doubt important, its various forms may depart from minimal physicalism. Physicalism, for example, historically proves to be a fairly dynamic thesis, ${ }^{4}$ at least in the details. Consider the fact that most (if not all) physicalists once equated being physical with being mechanistic. Surely, despite its historic universality, we no longer think this is an essential part of physicalism, particularly given the advent and widespread acceptance of quantum mechanics.

Minimal rather than mainstream physicalism is the view of interest, because the NFM constraint (constraining the very definition of the physical) has perfectly general implications as to what counts as physicalism. If any legitimate version of physicalism is compatible with panpsychism and fundamental mentality, then the NFM constraint wrongly defines it out of existence. If no legitimate version of physicalism is compatible with either, then the NFM constraint is at least permissible if not rightly imposed. The perfect generality of minimal physicalism (i.e., its feature of capturing what is essential to all versions of physicalism) therefore makes it the relevant view throughout the following.

\footnotetext{
2 Compare Galen Strawson (2006).

3 'Minimal physicalism' is a term that goes back at least to David Lewis (1983).

4 See, e.g., Bas van Fraassen (2002, pp. 49-61).
} 


\section{Getting started: Lewis's "panpsychistic materialism" and the NFM constraint}

The most developed part of the debate over the NFM constraint concerns whether physicalism is compatible with panpsychism. Following the literature, I focus (at least to start with) on the distinct issue of whether physicalism is compatible with panpsychism. I later turn to whether physicalism is compatible with fundamental mentality.

Lewis (1983) briefly argues that physicalism and panpsychism are metaphysically compossible theses, or that what he labels "Panpsychistic Materialism" is metaphysically possible. In support of this he writes the following:

It is often noted that psychophysical identity is a two-way street: if all mental properties are physical, then some physical properties are mental. But perhaps not just some but all physical properties might be mental as well; and indeed every property of anything might be at once physical and mental. (Lewis 362363)

Stoljar (2001a) reasons to the same conclusion and even, in doing so, cites the above passage:

[...] no matter how implausible and outlandish it sounds, panpsychism per se is not inconsistent with physicalism [cites Lewis here]. After all, the fact that there are some conscious beings is not contrary to physicalism-why then should the possibility that everything is a conscious being be contrary to physicalism? (Stoljar, §10)

Such compatibility is clearly in tension with the NFM constraint. According to it:

The NFM Constraint No fundamental physical entity (or property) - and no relatively fundamental physical entity (or property) — can be mental. ${ }^{6}$

This entails that physicalism cannot be true in a panpsychistic world since such a world contains fundamental mentality (as well as relatively fundamental mentality). ${ }^{7}$ This leads pro-NFMers, notably Wilson (2006), to deny Lewis and Stoljar's claim. I now turn to Wilson's argument and a development of it that I call the 'parts argument'.

\section{Wilson's argument and the parts argument for physicalism's incompatibility with panpsychism}

Wilson's argument comes in response to Stoljar. According to her, Stoljar offers the following argument:

\footnotetext{
5 See Stoljar 2001b, 2001c, where he presents the object-based definition of "the physical". Here he further illuminates what he says in this passage.

6 Compare Wilson's formulation (Wilson 2006, p. 72). She requires that fundamental physical entities (perhaps including properties) neither possess nor bestow mentality (Wilson 72).

7 Or so one might think. I soon question whether all panpsychistic worlds include fundamental mentality.
} 
1. That there are some conscious beings is compatible with physicalism.

2. Given (1), there is no principled reason not to allow that the possibility that all beings are conscious is compatible with physicalism.

Therefore, panpsychism is compatible with physicalism. (Wilson 78)

She denies premise two with the following counterargument:

[...] (most) physicalists believe "that there are some conscious beings is compatible with physicalism"; but this is because they think that consciousness (like mentality generally) is nothing over and above configurational physical goings on [...], not because they think that any [emphasis mine] physical entities are themselves conscious [...]. Hence [...] [physicalism is] compatible with there being some (non-fundamental) conscious beings yet incompatible with all beings - including relatively fundamental beings-being conscious. (Wilson 79)

Wilson (2005) here (in sentence one) commits all physicalists to what I call "the Configuration Principle" ${ }^{\circ}$ :

The configuration principle Only highly-configured physical entities are conscious (or mental in any way $\left.{ }^{9}\right){ }^{10}$

Accordingly, she reasons (in sentence two) that not all entities can be conscious, because "relatively fundamental entities" are among those entities. (Presumably, she also assumes that absolutely fundamental entities are among the totality of entities as well. ${ }^{11}$ ) Hence, the argument relies upon the basic assumption, one that many will find quite natural, that the totality of entities includes non-highlyconfigured entities of various sorts (both fundamental and relatively fundamental).

Here, a slight complication arises. Is this second assumption about the totality of entities in the actual world or in every (non-empty) possible world ${ }^{12}$ ? If the assumption is the former, then Wilson's premises are as follows:

(1) Physicalism includes or entails the Configuration Principle (the principle that only highly-configured physical entities are conscious).

\footnotetext{
$\overline{8}$ Wilson might mean to exclude physicalists who are eliminativists about the mental. She presumably has such theorists in mind when including the parenthetical hedge 'most' at the beginning of sentence one. Though interesting arguments might exist for the view that minimal physicalism is incompatible with mentality, I here put this view to the side. For, it is surely an extremely controversial view (if not flatout wrong) and beyond the scope of this paper. For present purposes I therefore assume that minimal physicalism is compatible with mentality and take Wilson to commit all physicalists to the Configuration Principle.

${ }^{9}$ In what follows I drop this parenthetical addition, though I assume it to be there implicitly.

${ }^{10}$ Wilson links "configurational physical goings on" with what she calls "relatively non-fundamental" physical beings. This suggests that the 'highly' in 'highly-configured' is appropriate since "relatively fundamental" physical beings might be configured as well, though perhaps to a lesser degree.

11 In fact, she may be assuming that truly fundamental beings are a species of relatively fundamental beings.

12 The relevant domain, if desired, may be restricted to every (non-empty) physicalist possible world. This may be done throughout the discussion.
} 
(2) The totality of entities in the actual world includes non-highly-configured entities.

If the assumption is the latter, the second premise is instead $2^{\prime}$ :

$\left(2^{\prime}\right)$ The totality of entities in every (non-empty) possible world includes nonhighly-configured entities.

Unfortunately, the passage does not make it clear which second premise Wilson has in mind. However, the issue does. ${ }^{13}$ The NFM constraint constrains the very definition of "the physical", thus giving it perfectly general modal implications about how to understand physicalism. So, the relevant question is whether physicalism and panpsychism can both be true in any (non-empty) possible world. (1) and (2) are clearly not up to the task of showing that they cannot be.

Wilson's argument therefore must consist of (1) and $\left(2^{\prime}\right)$ :

(1) Physicalism includes or entails the Configuration Principle.

$\left(2^{\prime}\right)$ The totality of entities in any (non-empty) possible world includes nonhighly-configured entities. ${ }^{14}$

(3) Therefore, physicalism and panpsychism cannot both be true in any (nonempty) possible world.

But, why should Wilson (or anyone) think $\left(2^{\prime}\right)$ is true?

A reasonable assumption to make here is that anyone who accepts $\left(2^{\prime}\right)$ also accepts what I call the 'Parts Principle':

The parts principle Every possible highly-configured entity has an entity that is not highly-configured as a proper part. ${ }^{15}$

To see why, suppose, for reductio, that $\left(2^{\prime}\right)$ is true and that the Parts Principle is false. Then, some possible highly-configured entity $(\mathrm{H})$ has no non-highlyconfigured entities as proper parts. A possible world consisting only of $\mathrm{H}$ and H's proper parts would then be a (non-empty) possible world in which no non-highlyconfigured entity exists. Hence $\left(2^{\prime}\right)$ is contradicted, showing that $\left(2^{\prime}\right)$ entails the Parts Principle. ${ }^{16,17}$

\footnotetext{
13 Wilson, after all, claims to show that physicalists and non-physicalists alike have good reason to impose the NFM constraint (Wilson 70).

14 See footnote 12 .

15 The relevant domain here also could be restricted to physicalist possible worlds.

16 In fact, the Parts Principle entails $2^{\prime}$ ) as well. For, suppose the Parts Principle is true. It is a logical truth that every (non-empty) possible world contains an entity that $i s$ highly-configured or one that is not highly-configured. By the Parts Principle, the former worlds contain a non-highly configured entity. Any of the latter worlds, ex hypothesi, contain a being that is not highly-configured. So, if the Parts Principle is true, so is $2^{\prime}$ ).

17 I thank the reviewer for bringing the following rebuttal to my attention. It goes something like this: Assume, for the sake of argument, $2^{\prime}$ ). Then, consistent with this, there's a possible world w with at least two entities (say) a and b: $a$ is not highly-configured, whereas $b$ is and has only highly-configured parts. The possibility of a world like w (i.e. one that contains something like b) contradicts the Parts Principle. So, $2^{\prime}$ ) can be true even if PP is not. That is, the Parts Principle may entail $2^{\prime}$ ) but not vice versa.

I guess I am assuming that if an object can exist in a world, then an intrinsic duplicate of it exists in a world containing only it and its parts. If that is right, then if a world like w exists, a world w* also exists
} 
Besides providing a reason for $\left(2^{\prime}\right)$, the Parts Principle also provides a new and crafty argument for (3), that is, once combined with (1). Specifically, any physicalist world containing one conscious and hence highly-configured entity now contains an entity that is not highly-configured and hence not conscious. This leads to the surprising result that the mere existence of one conscious entity in a physicalist world would entail the existence of an unconscious one, thus falsifying panpsychism.

The following argument, what I call the 'parts argument', is therefore a valid argument:

(1) Physicalism includes or entails the Configuration Principle.

$\left(2^{\prime \prime}\right)$ The Parts Principle is true.

(3) Therefore, physicalism and panpsychism cannot both be true in any (nonempty) possible world.

Wilson, in the passage, is clearly very far from formulating or explicitly endorsing the Parts Principle or suggesting it is the second premise in her argument. Still, I prefer this argument to (what is more clearly) her argument because of the just-observed theoretical potence of the Parts Principle. Besides, problems for the Parts Principle are problems for $\left(2^{\prime}\right)$, given the (two-way) entailment between them. It is this argument that I now analyze and consequently reject.

\section{Against the parts argument}

\subsection{Does physicalism entail "Configurationism"?}

Must all physicalists be committed to the Configuration Principle? Or, equivalently: Does physicalism entail what I call 'configurationism'? It is difficult to say, especially given the real threat of begging the question. For, whether one accepts the NFM constraint likely decides how one answers this. But, the answer here is ultimately supposed to tell us (by figuring into the parts argument) whether to accept the NFM constraint.

To find neutral ground it might be tempting to shift the concern to mainstream physicalism (i.e., the majority view of those who currently consider themselves physicalists). That way one can get an independent handle on what (selfproclaimed) physicalists currently believe. Then, one could turn to the question of whether that view (whatever it is) includes or entails configurationism.

This, unfortunately, is not an option. For, again, minimal-not mainstreamphysicalism is the view at issue. Accordingly, Lewis also explicitly concerns himself with minimal physicalism when discussing Panpsychistic Materialism, and so too with Stoljar, who is following Lewis.

As for minimal physicalism, it certainly does not seem to entail configurationism. Jaegwon Kim, for example, attributes three theses to minimal physicalism, none of

Footnote 17 continued

which contains only $b$ (which is highly-configured) and its (every single one of them, highly-configured) parts. This is not consistent with $2^{\prime}$ ). So, though the existence of a world like w may at first seem consistent with $2^{\prime}$ ), it ultimately is not all things considered. 
which is the Configuration Principle. They are: mind-body supervenience, mindbody dependence, and an anti-Cartesian principle. ${ }^{18}$ Lewis, in contrast, only requires a supervenience thesis, as does (e.g.,) Chalmers. ${ }^{19}$ Prominent accounts of minimal physicalism, then, do not include the principle. Nor is it obvious that any of these theses, either separately or combined, entail it. It therefore is at best questionable that physicalism entails configurationism. So much for premise one.

\subsection{High configuration and worlds without simples}

The second premise of the parts argument (the Parts Principle) is equally problematic if not more so. If being "highly-configured" is simply a matter of having a large number of parts, everything in an infinitely decomposable world is highly-configured, including every proper part of anything. Hence, if infinitely decomposable worlds are possible, the Parts Principle is not a necessary truth. ${ }^{20}$

The Parts Principle, then, is (most likely) contingent. This means physicalism is logically compatible with panpsychism even if minimal physicalism were to entail the Configuration Principle. For, physicalist worlds exist in which the Configuration Principle holds (worlds where everything that is conscious is highly-configured) but in which everything is (infinitely) highly-configured, thus allowing everything to be conscious.

To control for this, one could revise the Parts Principle to make it something both similar to the original and plausibly non-contingent. Ultimately, however, this fares just as poorly.

For example, one promising revision of the principle is:

The revised parts principle Every possible highly-configured entity has an nlevel proper part (for some sufficiently high value of $n$ ).

$\mathrm{X}$ is a "1-level" proper part of $\mathrm{Y}$ if $\mathrm{X}$ is a proper part of $\mathrm{Y}$; "2-level" if $\mathrm{X}$ is a proper part of a proper part of $\mathrm{Y}$; and so forth. ${ }^{21}$ The principle basically says, then, that every highly-configured physical entity has at least one more basic part, where the degree to which it is more basic is specified by $n$. If $n$, for example, is high, then every highly-configured physical entity has a very much more basic part. $^{22}$

\footnotetext{
18 See Kim 1996, pp. 9-13.

19 See Lewis 1983, pp. 361-64 and Chalmers 1996, pp. 41-42.

20 Denying the possibility of such worlds is, of course, one option in logical space, though not a very plausible one. A different option is to deny either that physicalism can be true in an infinitely decomposable world or that the physical can exist in such a world, in which case the Parts Principle would not need to be a necessary truth. This, first of all, would be an addition to the present argument. But, second, room for deep skepticism about either denial certainly exists as well.

21 Of course, every n-level part is also an $n-1$ level part, but that doesn't affect the argument.

22 An alternative way of fleshing out 'relatively fundamental' is implicit here. Something can of course be relatively fundamental in that a relatively small number of simple parts compose it. But, as suggested here, something can be relatively fundamental (merely) in that it is a certain kind of building block (i.e., an n-level proper part) of something else. These two senses of the term 'relatively fundamental' are not necessarily co-extensive (though their extension, in some possible worlds, can partially or wholly overlap).
} 
This, however, introduces a new problem. For, though the Revised Parts Principle is not contingent (even holding in infinitely decomposable worlds), it does not combine with the Configuration Principle to rule out panpsychism in physicalist worlds. That is, for all the Revised Parts Principle says, some infinitely decomposable world exists in which every proper part of a highly-configured physical entity is itself a highly-configured physical entity, hence one that could be conscious consistent with the Configuration Principle.

One might introduce a third principle:

The N-level principle Any n-level part of a highly-configured entity is not conscious.

This, however, is highly implausible. For example, humans themselves could be n-level parts of some unconscious but highly-configured entity, in which case the principle denies consciousness to humans.

A better principle might be:

The revised N-level principle Any n-level part of a conscious highly-configured entity is not conscious.

But it is logically possible that conscious entities, in some world, form a proper part of larger entities that are themselves conscious. In fact, even in the regular world, split-brain experiments suggest that the larger consciousness of the self is composed of two conscious parts, each corresponding to one of the hemispheres. Whether or not that is the case, such a scenario is certainly possible. It is not clear why something similar could not be possible for such "n-level entities" (i.e., entities that are n-level parts of other conscious ones).

In conclusion, no obvious replacement for the Parts Principle is both plausibly non-contingent and completes the argument. One must continue adding to the argument more (probably contingent ${ }^{23}$ ) principles in order to make it work or perhaps try building more than configurationism into minimal physicalism (which is questionable at configurationism). The parts argument, then, is in serious trouble if not outright hopeless.

\section{Refining the debate}

It would be good if the pro-NFMer could avoid the prior issue altogether, i.e., the issue of whether physicalism is compossible with panpsychism. For, as far as the prior discussion goes, it seems that physicalism is in fact compatible with panpsychism, at least in infinitely decomposable worlds.

As luck would have it, a natural reading of the constraint exists that suggests this issue is in fact avoidable. To see this, recall what the NFM constraint says:

The NFM constraint No fundamental physical entity (or property)-and no relatively fundamental physical entity (or property)—can be mental.

$\overline{23}$ I.e., contingent even within the restricted domain of physicalist worlds. 
A pro-NFMer could plausibly take 'relatively fundamental physical entity' to mean the following:

(i) a physical entity that is decomposable into no more than $\mathrm{m}$ simple parts ${ }^{24}$

On this interpretation, infinitely decomposable worlds are beside the point. For, infinitely decomposable worlds contain no simples of any sort and hence contain no fundamental physical entities or even (in the above sense) relatively fundamental physical entities. The constraint, as such, is not designed to rule out panpsychism in infinitely decomposable physicalist worlds.

Thankfully, one topic is undeniably relevant to the NFM constraint, no matter how one interprets the term 'relatively fundamental physical entity'. For, the constraint is a claim about fundamental physical entities, no matter what else it is a claim about. One question, then, is clearly relevant: Is physicalism compatible with fundamental mentality? If it is, this is fatal for the NFM constraint. ${ }^{25}$

\section{The argument from anti-dualism for physicalism's incompatibility with fundamental mentality}

To begin addressing this question, consider one simple argument for the negative answer (Wilson 2006):

Given that physicalism is an anti-dualist doctrine, [...] [the boundaries of the physical] may not stretch so far as to encompass fundamental mentality. ${ }^{26}$ Hence physicalists (and their rivals) have good reason to impose the NFM (no fundamental mentality) constraint on their operative account of the physical. (Wilson 70)

The argument's two premises are:

(1) Physicalism is an anti-dualist doctrine.

(2) Anti-dualist doctrines are incompatible with fundamental mentality.

(1) and (2) definitely entail that:

Physicalism is incompatible with fundamental mentality.

But, Wilson suggests they entail:

(3) “[...] [That] physicalists (and their rivals) have good reason to imposethe NFM [i.e., the no fundamental mentality] constraint on their operative account of the physical (Wilson 70).”

\footnotetext{
${ }^{24}$ See footnote sixteen for a possible alternative.

25 Though panpsychism could be worked back into the discussion, it is completely inessential to do so. The core issue is whether fundamental physical entities can be mental. If they cannot be mental, then of course it is true that, a fortiori, panpsychism is false in a world with such entities. But, that is more of an afterthought.

26 The full sentence reads: Given that physicalism is an anti-dualist doctrine, then while (in response to the first horn of Hempel's dilemma) the physics-based boundaries of the physical may stretch, they cannot stretch so far as to encompass fundamental mentality (Wilson 70).
} 
Call this argument - the argument from (1) and (2) to (3) - the "argument from anti-dualism".

\section{Against the argument from anti-dualism}

\subsection{Two senses of 'fundamental mentality'}

It is uncontroversial that physicalists must avoid fundamental mentality in one special sense. All should agree the most basic thesis of physicalism is everything (including the mental) is physical. And, all should agree this thesis, in turn, is incompatible with the following:

(i) that mental things exist that are not physical

and

(ii) that mental properties exist that are not even "dependent" 27 physical properties.

A view that rejects either (i) or (ii) embraces mentality as ontologically fundamental, which is one sense of 'fundamental mentality':

Fundamental mentality $(1)=$ Mentality that is fundamental either mental substances/objects are ontologically fundamental (meaning they are not themselves identical to, metaphysically supervenient on, reducible to, etc., physical substances/ objects); or mental properties are ontologically fundamental (meaning they are not themselves physical properties or identical to, metaphysically supervenient on, etc., physical properties).

However, a different sense of 'fundamental mentality' is involved in the NFM constraint. The constraint says that, on pain of not being physical, a fundamental physical entity cannot be mental. If such an entity could be mental, this would be (an instance of) what the pro-NFMer calls "fundamental mentality", providing a second sense of the term:

Fundamental mentality (2) = Mentality that is instantiated by a fundamental physical entity i.e., something is a fundamental physical entity and it instantiates at least one mental property, ${ }^{28,29}$

\footnotetext{
${ }^{27}$ By 'dependent physical property' I mean a property that somehow metaphysically depends on normal physical properties (e.g., property $\mathrm{P}_{1}$ metaphysically supervenes on a normal physical property $\mathrm{P}$; a normal physical property, $\mathrm{P}$, realizes $\mathrm{P}_{1}$ ).

${ }^{28}$ Note that, strictly speaking, this second sense is incoherent according to the NFM constraint. If a mental property applies to something fundamental, it cannot be physical. So, on this view, it is logically impossible for mentality to apply to a fundamental physical thing.

${ }^{29}$ Referring to this as "fundamental mentality" is potentially misleading. Whereas the adjective 'fundamental' appears to apply to the noun 'mentality', it really applies to the physical entity that instantiates the mental property. Formalizing things helps bear this out. Let 'Px', 'Fx', 'Mx', and 'Iyx' respectively stand for ' $\mathbf{x}$ is physical', ' $\mathbf{x}$ is fundamental', ' $\mathbf{x}$ is a mental property', and ' $\mathbf{x}$ instantiates $\mathbf{y}$ '. The formalization, then, is: $(\exists x)(P x \&$ Fx \& ( $\exists y)(M y \&$ Ixy)). The predicate ' $F$ ' clearly applies not to $y$ but instead $\mathrm{x}$.
} 
For example, ${ }^{30}$ compare Wilson's fuller definition of "the (basic ${ }^{31}$ ) physical" (Wilson 12, bold print mine):

The physics-based NFM account: An entity existing at a world $w$ is physical if and only if:

$\left(i^{\prime}\right)$ it is treated, approximately accurately, by current or future (in the limit of inquiry, ideal) versions of fundamental physics at $w$, and

(ii) it is not fundamentally mental (that is, does not individually [...] possess [...] mentality ${ }^{32}$ ).

Though the phrase 'fundamentally mental' in condition (ii) may (misleadingly) suggest fundamental mentality (1), the clarification (in bold) makes it clear that sense two is at issue (in part if not exclusively). ${ }^{33}$

If these two senses of the term seem equivalent, notice that fundamental mentality (2) leaves it quite open whether the mental property itself is fundamental. Consider, for example, the logically consistent belief that a fundamental physical entity instantiates a mental property (M), but only by virtue of instantiating physical properties upon which M metaphysically supervenes. This view clearly avoids ontologically fundamental mentality, while admitting fundamental mentality (2).

This of course assumes that a fundamental entity (an electron, say) can have nonfundamental properties. This is certainly not without precedent. For example, few would deny that electrons can have the properties (i) being within two miles of Lake Tahoe, (ii) weighing $9 \times 10^{-28} \mathrm{~g}$ or weighing $9.01 \times 10^{-28} \mathrm{~g}$, (iii) having a mass, or (iv) having some realized physical property $P_{n}$. Yet these are all orthodox examples of non-fundamental properties.

As for the pro-NFMers, Wilson, to my knowledge, takes no stance on the issue of whether fundamental entities can have non-fundamental properties. Her physicsbased NFM account allows for it. Levine (2001, p. 12) formulates physicalism (before imposing the NFM constraint) as: Only the fundamental properties of physics are instantiated in a basic way [i.e., are realized by no other properties]; all others, particularly mental properties, are instantiated by being realized by the instantiation of other properties. This certainly leaves room for fundamental entities possibly instantiating non-fundamental properties and his second formulation (postNFM constraint) does the same.

\footnotetext{
30 Also, see Levine 2001, p. 20.

31 All other physical things are to later be defined in terms of these basic physical things. It is a widespread strategy to split the task of defining "the physical" into these two parts.

32 Or, without omissions: "that is, does not individually either possess or bestow mentality (Wilson 12).".

33 Wilson might be running the two senses together. In fact, throughout the paper, she seems to slip back and forth between fundamental mentality (1) and fundamental mentality (2), indicating a failure to properly distinguish the two. On the other hand, she may be assuming that mental properties would be fundamental properties if they are (allowed to be) posited in fundamental physics, in which case fundamental mentality (2) would be at issue. (Perhaps, then, we should exclude mentality from the posits of physics (as opposed to excluding them from what properties physical entities can possibly instantiate).) In any case, condition (ii) (as per the parenthetical clarification) rules out the instantiation of mental properties by a physical entity regardless of whether they are fundamental properties.
} 
8.2 The argument from anti-dualism disambiguated

With this distinction in hand, one can (and needs to) disambiguate the anti-dualist argument. One way of doing so is as follows:

(1a) Physicalism is an anti-dualist doctrine.

(2a) Anti-dualist doctrines are incompatible with fundamental mentality (1).

(3a) So, physicalism is incompatible with fundamental mentality (2), giving physicalists (and their rivals) reason to impose the NFM constraint.

The premises are not controversial and the conclusion is the right one. But, the argument equivocates on the two senses of 'fundamental mentality'.

To correct for this, one only needs to add a third premise. $\left(2 \mathrm{a}^{\prime}\right)$ is a natural candidate:

\section{$\left(2 \mathrm{a}^{\prime}\right)$ Fundamental mentality (2) entails fundamental mentality (1).}

This, however, is false. For, again, consider the logically consistent belief that a fundamental physical entity instantiates a mental property (M), but only by virtue of instantiating physical properties upon which $\mathrm{M}$ metaphysically supervenes. Fundamental mentality (2) certainly does not logically entail fundamental mentality (1). ${ }^{34}$

A final disambiguation of the argument completely omits reference to fundamental mentality (1):

(1a) Physicalism is an anti-dualist doctrine.

(2b) Anti-dualist doctrines are incompatible with fundamental mentality (2).

(3a) So, physicalism is incompatible with fundamental mentality (2), giving physicalists (and their rivals) reason to impose the NFM constraint.

But, why think (2b) is true? The likely explanation here is that one believes $\left(2 \mathrm{a}^{\prime}\right)$. But that, again, is false. Whether the reason or not, some other argument altogether is needed for $(2 b)$.

This second argument, no matter how it is interpreted, thus fails to establish the incompatibility of physicalism and fundamental mentality (2). There is no defensible reason, then, to think that "physicalists (and their rivals) have good reason to impose the NFM [...] constraint (Wilson 70)", at least not purely on the basis of physicalism's being an anti-dualist doctrine.

\section{A physicalist view of so-called fundamental mentality: a positive argument}

\subsection{The plan and preliminaries}

Is it the case that, as a definitional or conceptual truth, physical simples cannot be mental? I contend it is not. For, consider the following intuition pump:

\footnotetext{
${ }^{34}$ For those not convinced, see Sect. 9.
} 
Suppose you are operating an atom smasher and you think you have discovered a physical simple, i.e. a physical entity with no proper parts. You discover it has certain properties, like (say) spin, mass, certain effects on quarks, a definite spatial location when measured, and so forth. But, now, imagine God pays you a visit, assuring you this thing is indeed a simple but also that it has a mental property. Is one inclined to say "I guess that simple's not physical after all" or instead "I guess that physical simple has a mental property"? It has all the same properties as before, just one more than previously thought.

I would wager those answering honestly here incline toward the latter answer. Hence, we should be open to the conceptual coherence of fundamental mentality (2).

With this in mind, I now articulate a view that embraces fundamental mentality (2). It therefore openly violates both configurationism and what I call 'weak configurationism', i.e., the view that a less restrictive version of the Configuration Principle holds ${ }^{35}$ :

The revised configuration principle Only physical entities that are non-simples (i.e., beings with proper parts) can be conscious.

I then argue this view is rightly considered a physicalist view. If this is so, my main contention of the paper follows.

Note I am not endorsing or recommending the view. In fact, I expect the average reader to find it-considered alone at least-quite repugnant. That is fine. I contend it is a physicalist view, nothing more.

\subsection{Articulating the "FM" view}

Consider, then, a view that embraces fundamental mentality (2). It may be called, for want of a better name, the "Fundamental Mentality (or FM)" view. For the time being at least, sink the question of whether it meets the requirements of minimal physicalism, which I turn to in the next section.

The first part of the FM view provides its central definitions and one sufficiency condition. To begin with, the view's definition of 'physical object' is:

D1: An object is a physical object if and only if the object has properties $\mathrm{P}_{1}, \ldots$, $\mathrm{P}_{\mathrm{n}}$.

' $\mathrm{P}_{1}, \ldots, \mathrm{P}_{\mathrm{n}}$ ' is a placeholder for the "definitional" physical properties, i.e., those properties the collective having of which is enough to count an object as physical (whatever those may be).

For the sake of being more concrete, one possible way of filling in ' $\mathrm{P}_{1}, \ldots, \mathrm{P}_{\mathrm{n}}$ ' is to use the spatial location view (SLV). ${ }^{36}$ On this view, only one property, $\mathrm{P}_{1}$, is both

\footnotetext{
35 Less restrictive in that it allows (in principle) more to be conscious.

36 Ned Markosian, e.g., holds this view. See (Markosian 2000).
} 
necessary and sufficient for being a physical object, where $\mathrm{P}_{1}$ is the property of being spatially located. Substituting into D1 we get:

SLV: An object is a physical object if and only if the object has the property of being spatially located.

The FM view, however, is not wedded to this.

As to 'physical property', the view only provides a sufficiency condition (not a definition!), one that rides piggyback on the definition (D1) of "physical object":

S1: A property is a physical property if, as a matter of metaphysical necessity, it can be instantiated only by physical objects (i.e., objects having $\mathrm{P}_{1}, \ldots, \mathrm{P}_{\mathrm{n}}$ ). ${ }^{37}$

Finally, the view's definition of 'mental object' is:

D2: An object is a mental object if and only if it has a mental property.

The notion of 'mental property' is taken to be a primitive, understood without definition.

The second part of the FM view moves beyond definitions and sufficiency conditions to its metaphysical claims. The view is intended to be a physicalist view, therefore admitting no fundamental mentality in the problematic (first) sense, but admitting fundamental mentality (2).

First, M1 and M2 provide its physicalist ambition:

M1: All objects in the actual world, including mental objects, are physical objects.

and

M2: All mental properties that apply in the actual world are physical properties. ${ }^{38}$

Second, M3 takes a further stance on M2:

M3: Mental properties are not "definitional" physical properties, i.e., they play no role whatsoever in $\mathrm{P}_{1}, \ldots, \mathrm{P}_{\mathrm{n}}$ and yet, as a matter of metaphysical necessity, only physical objects can instantiate them.

This tells us why, on the FM view, mental properties are physical properties. It also helps make the view (relatively) more palatable since few are inclined to use

\footnotetext{
37 For any property $\mathrm{Q}$, the conjunctive property $\mathrm{P}_{1} \& \ldots \& \mathrm{P}_{\mathrm{n}} \& \mathrm{Q}$ meets this sufficiency condition. This conjunctive property, though, would only meet the condition because it requires that the conjunctive property, $\mathrm{P}_{1} \& \ldots \& \mathrm{P}_{\mathrm{n}}$ is instantiated and has nothing (necessarily) to do with $\mathrm{Q}$.

If one is not willing to count such a property as a (in some cases very unusual, often non-paradigmatic) physical property, then make the following restriction. For any conjunctive property of the form $\mathrm{P}_{1} \& \ldots$ $\& \mathrm{P}_{\mathrm{n}} \& \mathrm{Q}, \mathrm{Q}$ (alone) must also meet the sufficiency condition in order for $\mathrm{P}_{1} \& \ldots \& \mathrm{P}_{\mathrm{n}} \& \mathrm{Q}$ to be properly considered a physical property.

38 One may remove the 'mental' here to get a more general formulation of physicalism. As should be clear, I am here primarily interested in physicalism about the mind/the mental.
} 
mental properties in defining 'physical object' (even were they agreed to meet the sufficiency condition (S1) for being physical properties). ${ }^{39}$

Finally, M4 and M5 introduce "fundamental mentality":

M4: The actual world is not infinitely decomposable—it "bottoms out" in a layer of simples.

and

M5: One mental property applies to at least one simple.

Call the view with (this weak version of $)^{40}$ M5 the "minimalist" FM view, though the 'minimalist' is dropped in what follows. This, then, is the FM view.

\subsection{Does the FM view meet the requirements of minimal physicalism?}

The FM view claims mental properties meet the sufficiency condition (S1) for being a physical property. People will likely disagree with this crucial part of the view. Clearly, there is plenty else to disagree with. But, whether one accepts the view or any part of it is not the issue here.

The issue instead is whether the FM view is a physicalist view. This may be broken down into three sub-issues, which correspond to Kim's three criteria for minimal physicalism. Specifically, is the FM view (i) anti-Cartesian, (ii) such that it preserves mind-body dependence, and (iii) such that it preserves mind-body supervenience?

\subsubsection{Is the FM view anti-cartesian?}

M3 makes the FM view anti-Cartesian. It says, in part, that, as a matter of metaphysical necessity, only physical objects can instantiate mental properties. The linchpin of Cartesian dualism is the view that something could (possibly) be a thinking thing and yet not be an extended thing, which Descartes takes to show that extended substances and thinking substances are truly distinct. ${ }^{41}$ Plug any reasonable conception of the physical (say, the SLV) into D1 and the FM view is then, broadly speaking, anti-Cartesian. Substitute (say) is extended into D1 and the FM view then directly contradicts Descartes's actual view. That is anti-Cartesian enough.

\footnotetext{
39 Here, if anywhere, is where I think that physicalists should exclude mental properties (i.e., from the definitional physical properties). But, this is not to rule out fundamental mentality (2). In other words, it is one thing to say we should turn to (future/ideal/etc.) physics for the definitional physical properties and exclude mental properties from physics but quite another thing to add Wilson's condition (ii) (see p. 11) to the definition of "the physical".

40 An alternative M5 on the other end of the spectrum is: One mental property applies to every object in the actual world, including any simples or relatively simple objects. This would provide a panpsychistic version of the FM view. Of course, there are a whole host of FM views between.

41 Cf. Meditation Six (Descartes1998), $\uparrow$. There, Descartes relies on God to guarantee that what he can clearly and distinctly perceive as separate is really separable.
} 


\subsubsection{Does the FM view preserve mind-body dependence?}

The FM view clearly preserves mind-body dependence. According to the view, an object cannot even possibly (as a matter of metaphysical possibility) have a mental property (thus counting it as a mental object) without its first being a physical object. It therefore preserves a strong dependence of mental objects (minds) on physical objects (bodies) (i.e., objects having $\mathrm{P}_{1}, \ldots, \mathrm{P}_{\mathrm{n}}$ ).

\subsubsection{Does the FM view preserve mind-body supervenience?}

The FM view is purposefully constructed to avoid certain supervenience claims. This is because Kim's third criterion (and some people's sole criterion) for minimal physicalism may not be minimal enough (depending on how the claim is cashed out). This, however, is not the right place to get into such matters, though it is certainly worth flagging.

Thankfully, present purposes do not require this issue to be resolved. One only needs to add a sixth metaphysical claim (M6) to the FM view, in which case it surely preserves mind-body supervenience.

M6: All mental properties instantiated in the actual world metaphysically supervene on (non-mental) physical properties.

Crucially, M6 contradicts no other part of the FM view. Rather, it simply strengthens the FM view with respect to the relation said to hold between mental properties and (non-mental) physical properties. In fact, $M 6^{\prime}$ is consistent with the FM view as well:

M6': All mental properties instantiated in the actual world are realized by (nonmental) physical properties.

As normally conceived, $\mathrm{X}$ realizing $\mathrm{Y}$ entails the supervenience of $\mathrm{Y}$ on $\mathrm{X}$. Clearly, the FM view is easily made to preserve supervenience, all the while embracing fundamental mentality (2). So, if minimal physicalism requires that this third condition be met at all, the FM view can easily accommodate it.

\subsubsection{Conclusion}

The FM view, some way or another, meets all three of Kim's criteria for minimal physicalism. It is wholly unclear what else one could ask from a physicalist view. I conclude that the FM view is a physicalist view despite the fact that it embraces fundamental mentality (2). The only proviso is that one might need to add M6 (or perhaps $\mathrm{M6}^{\prime}$ ) to the view. This suggests that what really matters to maintaining physicalism is avoiding fundamental mentality (1), while fundamental mentality (2) is optional. 


\section{An irresistible objection}

\subsection{The objection}

Despite the disclaimers people likely will object along the following lines: Surely you do not believe that simples (should they exist), or say protons and quarks, are actually mental. No one believes that. People believe to the contrary that, just like clouds, peach pits, and sidewalks, quarks and the like are thoroughly non-mental. To believe that they are is pure madness.

\subsection{A caveat}

It is wrongheaded to think that if simples have mental properties, then they have mental properties just like ours. In fact, they might have proto-mental properties, i.e., properties that combine to form the mental properties we recognize at the macro-level. Take the following (toy) example. A simple has the property (X) of being disposed to create a complex entity that experiences pain when joined with another simple that has X. Neither of two X-bearing simples are in pain, so neither has a mental property that in any way resembles the ones with which we are familiar. Nonetheless, they have mental properties, broadly construed, since they have properties that combine to form qualia.

Perhaps allowing proto-mental properties to count as mental properties is to construe the notion too broadly (perhaps not). Nonetheless, there may be mental properties that are less like mental properties such as ours. Perhaps, for example, there in fact is something it is like to be a bat, but maybe it is very different than what it is like to be a human. Or, perhaps there is something it is like to be an octopus, or an insect, or Lewis's martians, or some gelatinous blob. Perhaps, even, mental states can exist that are not a gestalt of various modalities (like ours) but that are instead extremely simple. The theoretical possibilities are nearly limitless. Suffice it to say that if a simple has mental properties, then they need not be mental properties just like ours.

\subsection{Primary response}

To repeat, whether quarks or the like are actually mental is not at all central to the present issue. True, if one believed this and that such things are still physical, she would agree with the claim I actually make. But, just to be clear, the claim I actually make is that one may be (and is rightly consider to be) a physicalist while holding such a view, not that I or that anyone necessarily should hold it.

\subsection{A secondary response}

I do not believe quarks or the like are actually conscious, or that they are mental in any way. But nor, for the record, do I believe they are not. How anyone could know either way is a mystery to me. The same goes, for that matter, regarding clouds, 
peach pits, sidewalks, and so on. Like Malebranche's view of animals, ${ }^{42}$ the objector seems to overreach her epistemic warrant, likely expressing more of a prejudice than a critically held view.

One could argue, though, that we should resist postulating mental quarks on the same basis that we resist postulating anything for which there is a lack of evidence. For example, we resist postulating the existence of pixies living in the walls because there is no evidence for it, preferring outright denial here to safe agnosticism. In response, it ought to be said that that is correct for pixies. We do not, however, prohibit the postulation of additional properties where doing so may help us to explain extant phenomena. In the present case, we have an outstanding problem (the mind-body problem and the surrounding problems) with respect to which additional postulation might be helpful.

\section{Conclusion}

I conclude that the minimal thesis of physicalism is compatible with fundamental mentality (2), as well as panpsychism. This suggests the following argument:

(1) Legitimate versions of physicalism, like the FM view, can embrace "fundamental mentality", i.e., fundamental mentality (2).

(2) If we impose the NFM constraint, this rules out such versions of physicalism.

(3) Hence, advocates of the FM view (and its rivals) have good reason not to impose the NFM constraint on their operative account of the physical.

This result has clear implications toward current discussions of how to define the physical: however it is defined exactly, the NFM constraint goes too far. It also suggests, as noted in the introduction, that the physicalist's playing deck is deeper than normally supposed when encountering problems like the explanatory gap, the "hard problem" (Chalmers 1995), or whatever problem, including the classic mindbody problem. Whether it really ultimately helps raises further issues. But, to be perfectly frank, such a shift of focus is more than welcome given the apparent stagnation of the debate.

Acknowledgment Thanks to Adam Sennet, Bert Baumgaertner, Bradley Morris, Cody Gilmore, Donovan Wishon, Ian Spencer, James Blackmon, Joseph Levine, and an anonymous reviewer for comments on earlier drafts of this paper. Special thanks go to Bernard Molyneux for his patient tutelage throughout the entire process.

Open Access This article is distributed under the terms of the Creative Commons Attribution Noncommercial License which permits any noncommercial use, distribution, and reproduction in any medium, provided the original author(s) and source are credited.

\footnotetext{
42 "[Animals] eat without pleasure, cry without pain, grow without knowing it; they desire nothing, fear nothing, know nothing (Malebranche 394).”
} 


\section{References}

Chalmers, D. (1995). Facing up to the problem of consciousness. Journal of Consciousness Studies, 2(3), 200-219.

Chalmers, D. (1996). The conscious mind: In search of a fundamental theory. New York: Oxford University Press.

Descartes, R. (1998). Meditations on first philosophy (4th ed.). Indianapolis: Hackett Publishing Company.

Dowell, J. (2006). The physical: Empirical, not metaphysical. Philosophical Studies, 131(1), 25-60.

Kim, J. (1996). Philosophy of mind. Boulder: Westview Press.

Levine, J. (2001). Purple haze: The puzzle of consciousness. New York: Oxford University Press.

Lewis, D. (1983). New work for a theory of universals. Australasian Journal of Philosophy, 61(4), 343377.

Malebranche, N. (1970). Euvres complètes (Vol. II). Paris: J. Vrin.

Markosian, N. (2000). What are physical objects? Philosophy and Phenomenological Research, 61(2), $375-395$.

Stoljar, D. (2001a). Physicalism. Stanford Online Encyclopedia of Philosophy.

Stoljar, D. (2001b). The conceivability argument and two conceptions of the physical. Philosophical Perspectives, 15, 393-413.

Stoljar, D. (2001c). Two conceptions of the physical. Philosophy and Phenomenological Research, 62(2), 253-281.

Strawson, G. (2006). Realistic monism: Why physicalism entails panpsychism. In: A. Freeman (Ed.), Consciousness and its place in nature: Does physicalism entail panpsychism? (pp. 3-31). Charlottesville: Imprint Academic.

van Fraassen, B. (2002). The empirical stance. New Haven: Yale University Press.

Wilson, J. (2005, Draft). On characterizing the physical. http://www.bgsu.edu/downloads/cas/file27406. pdf.

Wilson, J. (2006). On characterizing the physical. Philosophical Studies, 131(1), 61-99. 